Journal of Engineering and Applied Sciences 14 (4): 1093-1099, 2019

ISSN: 1816-949X

(C) Medwell Journals, 2019

\title{
Wunderlich Curve Fractal Dipole Antenna for Dual-Band Wearable RFID Applications
}

\author{
${ }^{1}$ Ghufran M. Hatem, ${ }^{2}$ Ali J. Salim, ${ }^{3}$ Taha A. Elwi, ${ }^{2}$ Hadi T. Ziboon, ${ }^{2}$ Jaber H. Majeed and \\ ${ }^{2}$ Jawad K. Ali \\ ${ }^{1}$ Department of Communication Engineering, Al Najaf Technical College, Al Najaf, Iraq \\ ${ }^{2}$ Microwave Research Group, Department of Electrical Engineering, University of Technology, \\ Baghdad, Iraq \\ ${ }^{3}$ Department of Communication Engineering, Al-Mammon University College, Baghdad, Iraq
}

\begin{abstract}
In this study, a wearable textile tag dipole antenna is introduced as a candidate for use in RFID applications. The antenna structure had been designed based on a modified version of the Wunderlich fractal geometry of the second iteration. The proposed antenna is simulated with two form of substrate conventional and textile for traditional substrate it offered a dual band at 0.952 and $2.5 \mathrm{GHz}$ and when it modeled on a textile substrate it offers a dual-band response resonating at 0.952 and $2.7 \mathrm{GHz}$. Results show that the textile antenna presents acceptable radiation characteristics with peak gains of about $1.214 \mathrm{dBi}$ and read range $12.76 \mathrm{~m}$ for lower band and $2.704 \mathrm{dBi}$ with $4.9 \mathrm{~m}$ read range for upper band. The effect of the thread radius, the characterization of different textile material used as the substrate when nine textile materials are chosen for the compression and also the various layer of textile has been studied in this research. Modeling and performance characteristics are evaluated by using the commercially available EM simulator, the CST Microwave Studio.
\end{abstract}

Key words: Wearable antenna, textile antenna, RFID antenna, dual-band antenna, materials, simulator

\section{INTRODUCTION}

Wearable textile antennas have become occupied a considerable area of the research in the fields of RFID applications because of the high flexibility offered by these antennas. Recent challenges have made the designers of microwave antennas and passive circuits to seek out design techniques to produce compact size components with multiband responses. The various fractal geometries have been successfully verified as an attractive choice for the antenna (Ali, 2009; Ali and Ahmed, 2012; Ali et al., 2012a, b; Abdulkarim et al., 2013) and bandpass filter design.

In this respect, fractal geometries are specified by astonishing characteristics resulting that work has been done on antenna design based on this geometry, so that, one can obtain antennas have both features of fractal and textile antennas (Sangeetha and Caroline, 2016). Many research works have dealt with the application of fractal geometry in the design of textile antennas. Jalil et al. (2012), Koch fractal of the first iteration has applied to get a triple-band dipole antenna structure for wearable applications. While by Poonkuzhali et al. (2016), a second iteration Koch geometry is employed to gain a size miniaturization and bandwidth of $10 \%$. Also, Koch geometry with a little modification has been used as reported by Jalil et al. (2013). Minkowski fractal geometry and tuning holes have been utilized to achieve antenna for WLAN applications (Syed et al., 2015). A wearable textile patch antenna based on Sierpinski dragon fractal curve is proposed by Hatem et al. (2014).

In this study, a fractal-based dual-band textile antenna has been introduced. The proposed antenna was designed based on a modified Wunderlich fractal curve of the second iteration for different RFID applications. Modification of the proposed antenna is accomplished depending on the study of the distribution of current on the surface of the antenna structure. The proposed antenna has been tested with two modes of substrates; the conventional and the textile.

\section{MATERIALS AND METHODS}

The proposed antenna modeling: The geometry of the proposed second iteration printed fractal antenna is depicted in Fig. 1 with respect to the coordinate system. The antenna is supposed to be printed on Roger Rt/Duroid 5880 substrate with dimensions of

Corresponding Author: Ghufran M. Hatem, Department of Communication Engineering, Al Najaf Technical College, Al Najaf, Iraq 


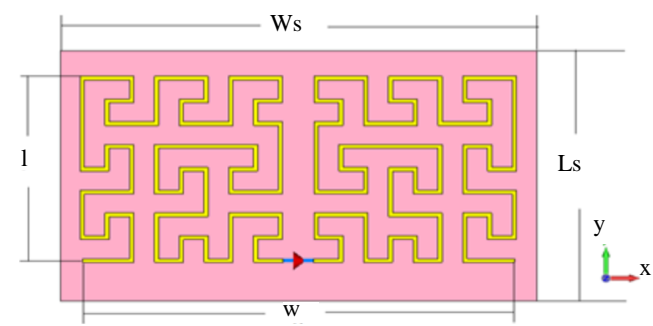

Fig. 1: The layout of the modeled 2nd iteration antenna with top view coordinate system

Table 1: Summary of the modeled antenna dimensions Symbols and their values of the

Antenna components proposed antenna $(\mathrm{mm})$

Radiator $\mathrm{w}=116.35, \mathrm{I}=55.46$

Substrate $\mathrm{Ws}=102.76, \mathrm{Ls}=85.5, \mathrm{~h}=3.175$

$(\mathrm{Ws} \times \mathrm{Ls})$ with a relative dielectric constant $=2.2$ and substrate thickness $\mathrm{h}=3.175 \mathrm{~mm}$. The antenna is excited using a $50-\mathrm{Ohm}$ probe feed technique. After some dimension scaling of the modeled antenna it seems to have a multiband response. Table 1 summarizes the dimensions of the modeled antenna.

\section{RESULTS AND DISCUSSION}

Performance evaluation of the modeled antenna: The antenna with the layout depicted in Fig. 1 has been modeled by with prescribed substrate. Simulation results reveal that the antenna offers a triple-band resonance within the sweep frequency of $0-3 \mathrm{GHz}$ with resonant frequencies at about $1.312,2.00$ and $2.277 \mathrm{GHz}$ as shown in Fig. 2.

The antenna response does not prevent the possibility of the existence of other resonances outside this frequency range. Table 2 shows the bandwidth of the proposed antenna for triple bands. From the results it was found that the proposed antenna doesn't satisfy RFID range frequencies (Bernat and Mansfield, 2008). To make the antenna match with RFID range, we fill the gaps in the previous design according to the current distribution path. The corresponding current distribution of triple bands has been shown in Fig. 3. The following steps are to choose the best feeding location to match with IC and the best chip impedance value.

After implementing these steps, the proposed Wunderlich dipole antenna will be as shown in Fig. 4. A parametric study of the effect of the capacitor value of the IC on the antenna return loss response within the sweep frequency of $0-3 \mathrm{GHz}$ is shown in Fig. 5, corresponding to a capacitor value variation of about $0.2 \mathrm{pF}$. The results imply that the antenna satisfies the requirement of RFID applications when $\mathrm{C}=0.9 \mathrm{pF}$. The antenna offers a dual-band resonance at 0.952 and $2.5 \mathrm{GHz}$.

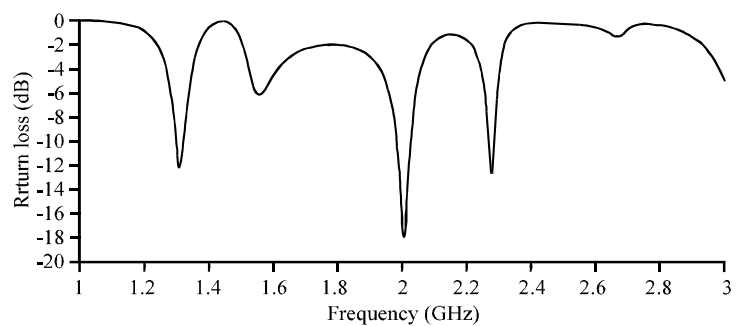

Fig. 2: Simulated return loss response of the resulting 2nd iteration Wunderlich based dipole antenna

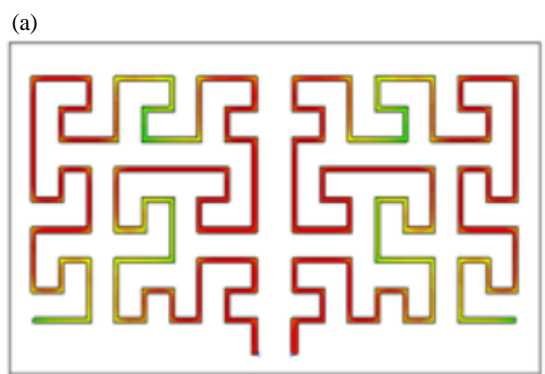

(b)

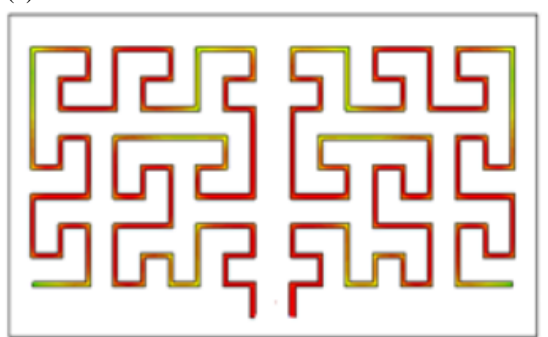

(c)
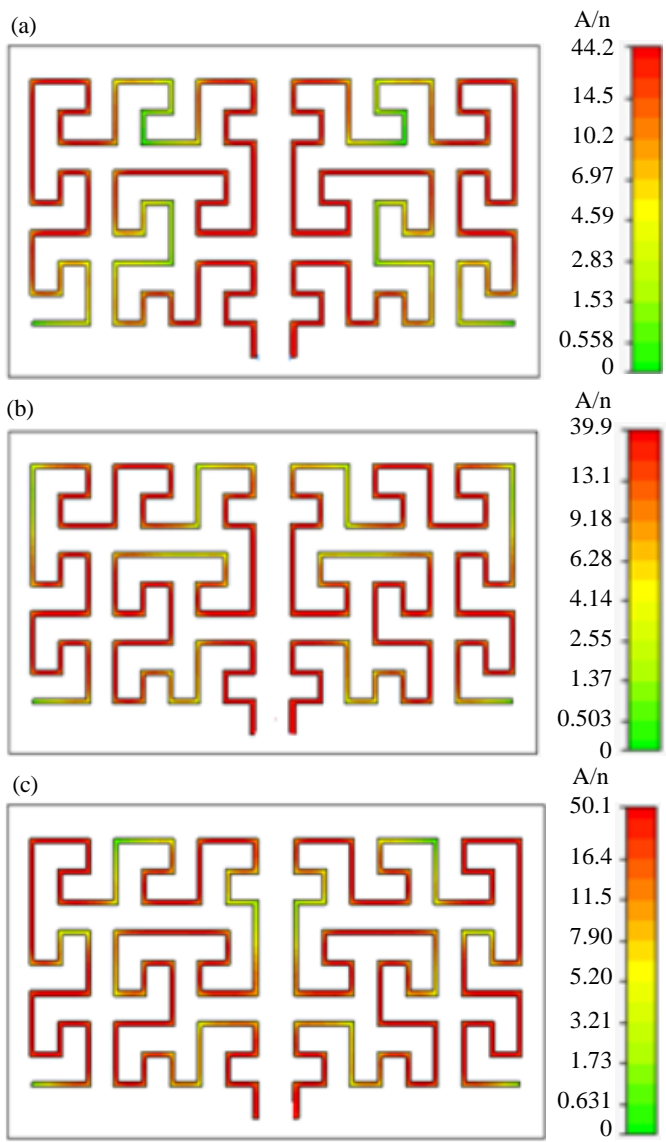

Fig. 3: Simulated current distributions on the surface of the resulting triple band antenna at: a) $1.321 \mathrm{GHz}$; b) $2.00 \mathrm{GHz}$ and c) $2.278 \mathrm{GHz}$

Table 2: Bandwidth of proposed antenna for triple bands

\begin{tabular}{lc}
\hline Resonant frequency $(\mathrm{GHz})$ & Bandwidth range $(\mathrm{GHz})$ \\
\hline 1.321 & $1.2986-1.3274$ \\
2 & $1.9806-2.0283$ \\
2.278 & $2.2671-2.2866$ \\
\hline
\end{tabular}

Antenna modeling with textile substrate: In this study, the proposed antenna is to be printed on material in the form of textile as the substrate with the same technique that was used by Hatem et al. (2015) with a 
relative dielectric constant $=1.8$ and with thread radius $\mathrm{r}=0.8 \mathrm{~mm}$. The antenna geometry is shown in Fig. 6.

The proposed antenna depicted in Fig. 6 has been modeled with the prescribed substrate and its

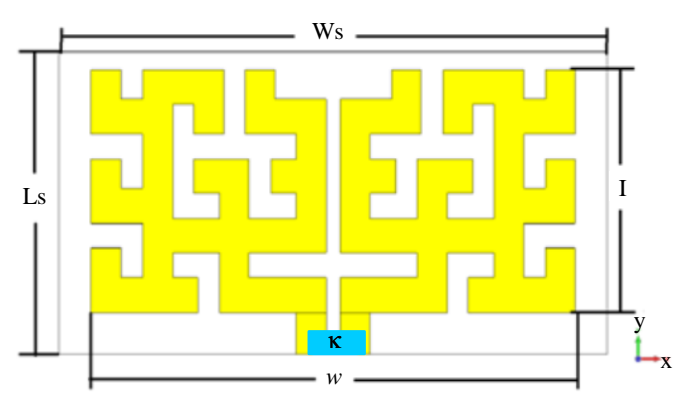

Fig. 4: The layout of the modified modeled 2nd iteration antenna with top view coordinate system matching with IC performance has been evaluated within the sweep frequency range (0-3) GHz. Simulation results reveal that the antenna offers a dual resonant behavior at the operating frequency of about 0.952 and $2.7 \mathrm{GHz}$ as shown in Fig. 7. The effect of thread density on the performance of the proposed antenna is investigated by sweep thread radius (r) $\mathrm{mm}$ variation from $0.5-0.9 \mathrm{~mm}$. The density of the threads within the substrate antenna area decreased as the thread radius was decreased. The antenna with $\mathrm{r}=0.9 \mathrm{~mm}$ has the highest density and the antenna with $\mathrm{r}=0.5$ has the lowest density. When the radius decreases, the frequency shifted to upper frequency as shown in Fig. 8. The more suitable result has occurred when the value of the radius is high. When the gap between threads has been increased, the tag antenna performance is deteriorated. The deterioration is because the added air in the textile substrate increased its permittivity then detuning the antenna and decreases the matching.

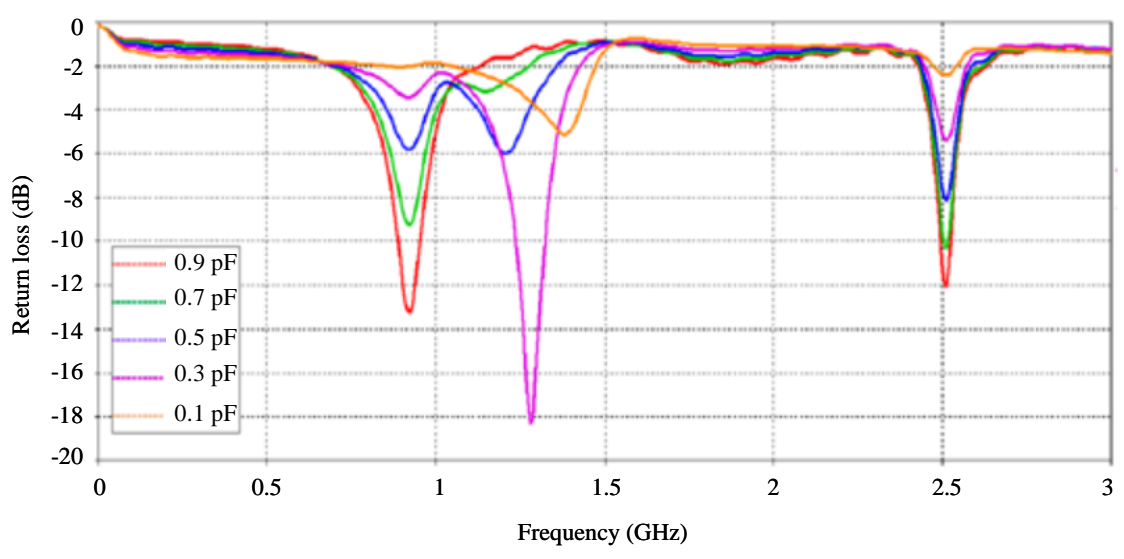

Fig. 5: Simulated return loss responses of the resulting 2nd iteration Wunderlich curve antenna with different capacitor values

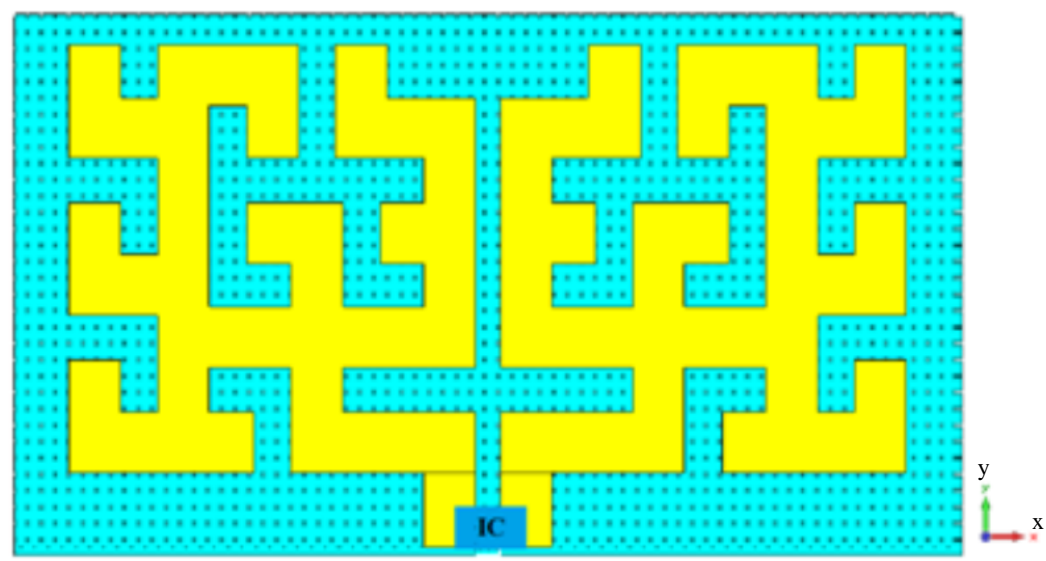

Fig. 6: The layout of the modeled 2nd iteration Wunderlich based textile antenna 


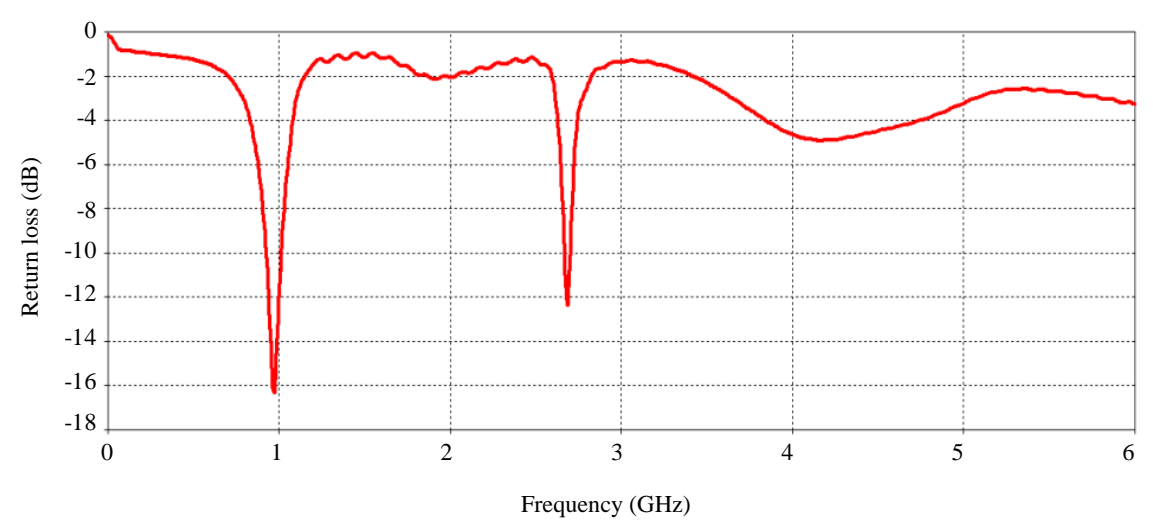

Fig. 7: The simulated return loss for the proposed antenna with the textile substrate

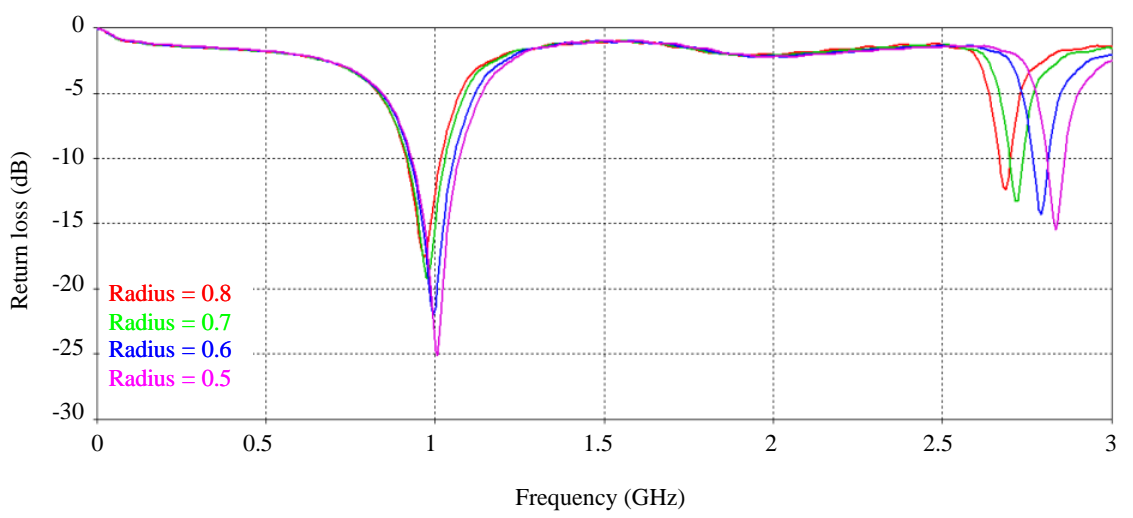

Fig. 8: Simulated return loss response for different values of thread radius

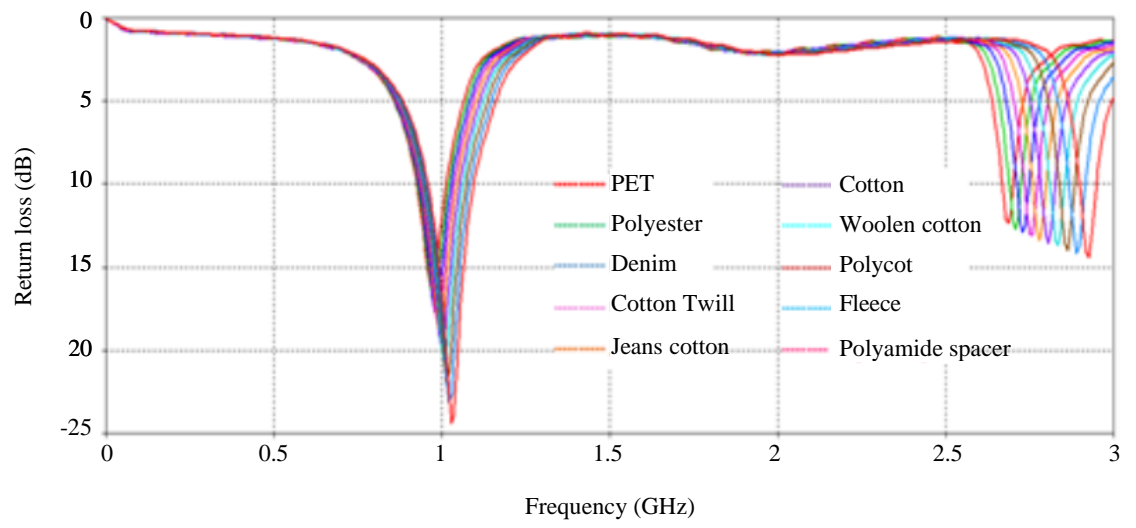

Fig. 9: Simulated return loss responses of the modeled antenna for different textile material

The effect of using different textile materials as the substrate on the antenna performance is studied by examining nine textile materials. Figure 9 shows the simulated return loss responses of the modeled antenna for different textile material.

The results show that the lower band has been no apparent change while for the upper band the resonant frequencies have been shifted to the right. The best results when satisfied for PET, denim and polyester. The surface current distributions generated in the antenna have been simulated at 0.952 and $2.5 \mathrm{GHz}$ as shown in Fig. 10 to get more insight into the EM characteristics of the proposed antenna. As the results of Fig. 10a implies, the resonance at $0.952 \mathrm{GHz}$ 

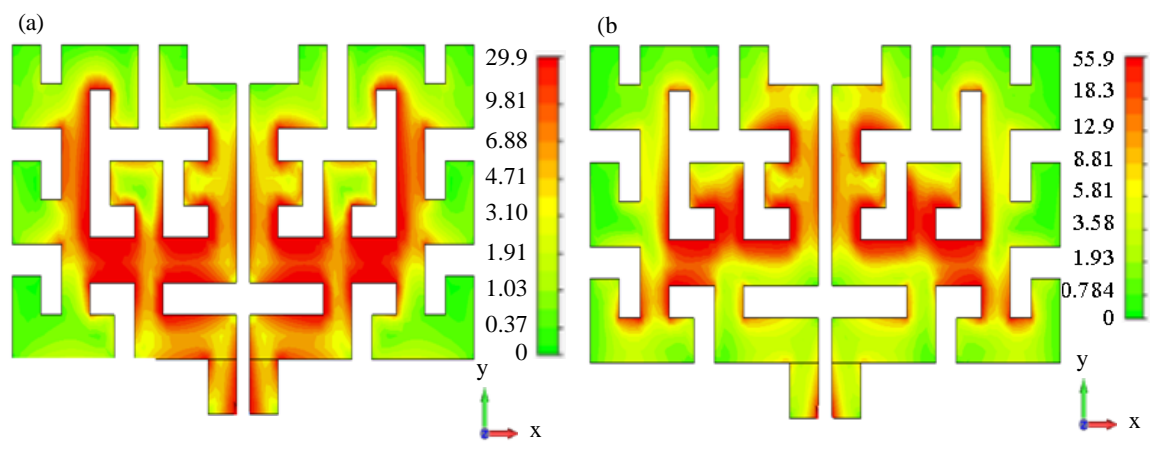

Fig. 10: Simulated current distributions on the surface of the resulting dual-band antenna at; a) $0.952 \mathrm{GHz}$ and b) $2.5 \mathrm{GHz}$
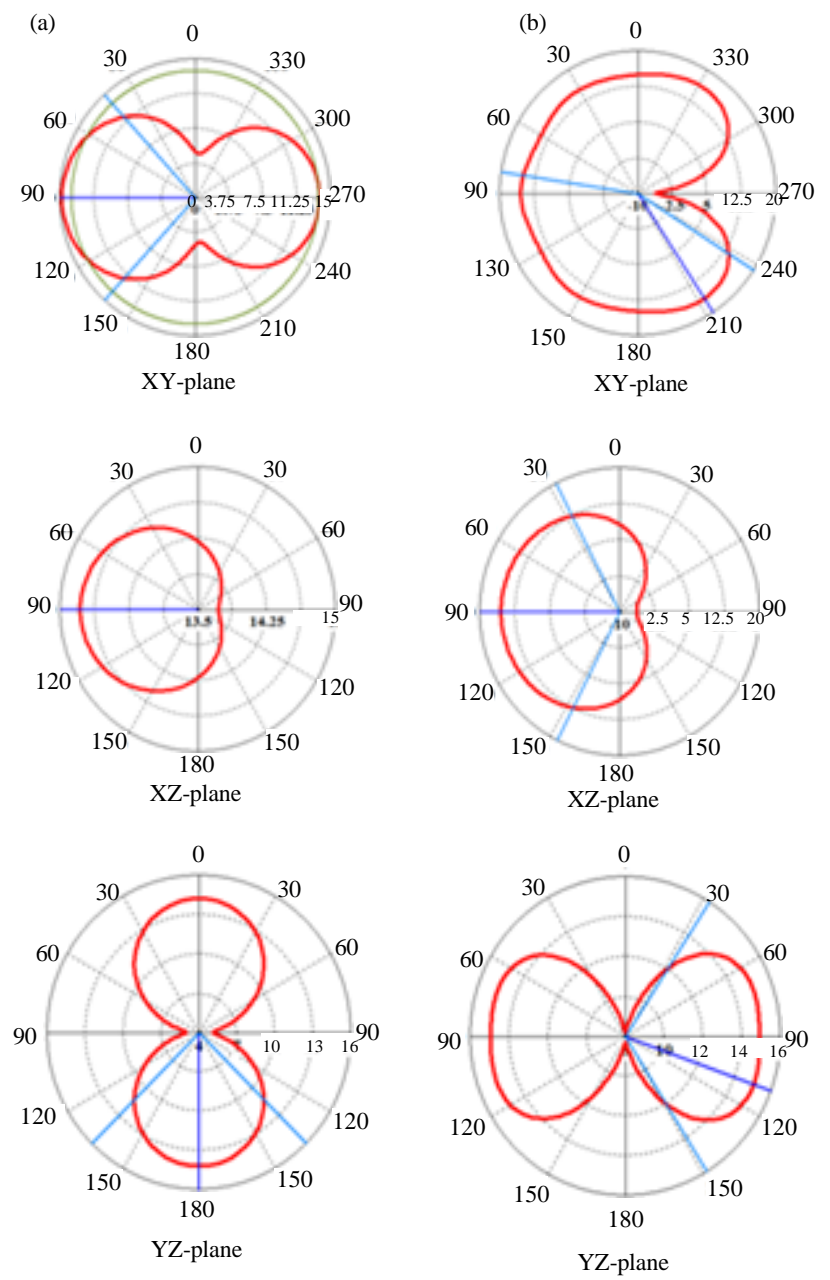

Fig. 11: Simulated far-field radiation patterns for the total electric field of the antenna shown in Fig. 5 at; a) $0.952 \mathrm{GHz}$ and b) $2.5 \mathrm{GHz}$

is attributed to the more extended surface current path as compared with that at $2.5 \mathrm{GHz}$ as shown in Fig. $10 \mathrm{~b}$.

However, at both resonant frequencies at the edges, small isolated conducting substructures with low current densities contained in the antenna structure with relatively low current flowing on their surfaces have a slight effect on its performance. Figure 11 shows the simulated far-field radiation patterns for the total electric field in the X-Y plane, the X-Z plane and the $\mathrm{Y}-\mathrm{Z}$ plane at 

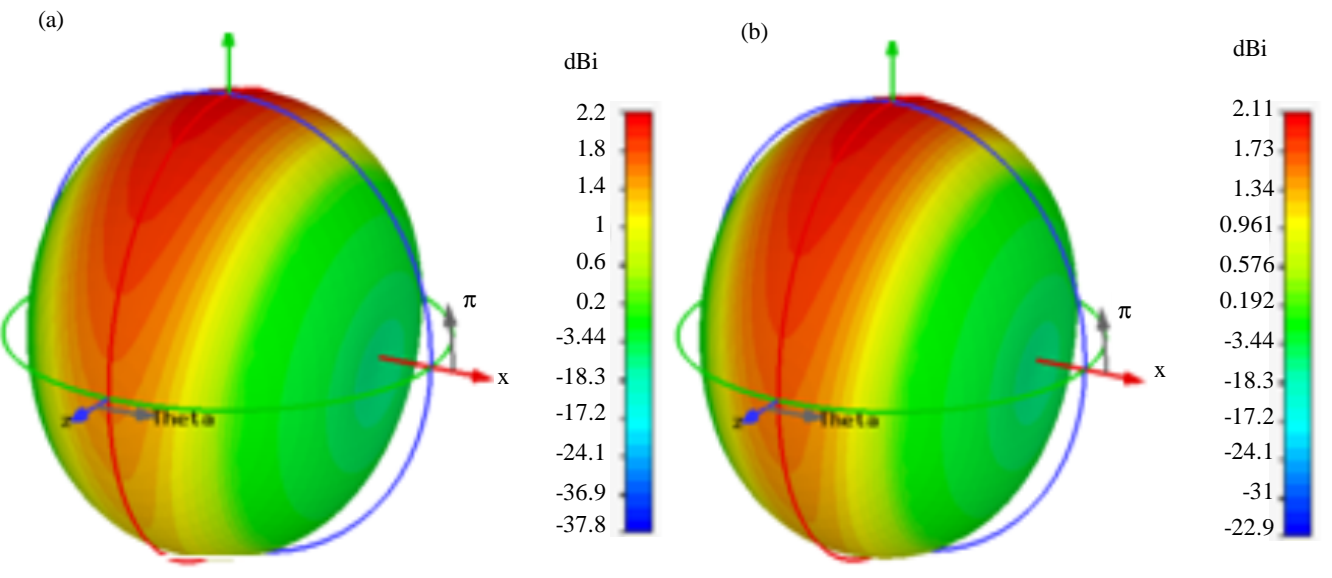

Fig. 12: Simulated 3D directivity of the resulting dual-band antenna at; a) $0.952 \mathrm{GHz}$ and b) $2.5 \mathrm{GHz}$

Table 3: Read range for Wunderlich curve antenna

\begin{tabular}{lcc}
\hline Substrate type/Gain $(\mathrm{dB})$ & Operating frequency $(\mathrm{GHz})$ & Read range $(\mathrm{m})$ \\
\hline Conventional & & \\
1.274 & 0.952 & 12.780 \\
2.448 & 2.500 & 5.217 \\
Textile & & \\
1.214 & 0.952 & 12.760 \\
2.704 & 2.700 & 4.900 \\
\hline
\end{tabular}

the center frequencies of the two resonant bands of the modeled antenna. As far as the radiation properties are concerned, Fig. 12 shows the simulated three-dimensional directivity radiation patterns of the resulting antenna. The directivity at $0.952 \mathrm{GHz}$, the center frequency of the lower band is $2.202 \mathrm{dBi}$ as shown in Fig. 12a whereas the directivity at $2.5 \mathrm{GHz}$ the center frequency of the upper band is $2.113 \mathrm{dBi}$ as shown in Fig. 12b.

The calculated read ranges of the antenna printed on a conventional and textile substrate are summarized in Table 3. The reader's output power is set to $4.0 \mathrm{~W}$ EIRP and the threshold power required to turn on the NXP chip $(-17.5 \mathrm{dBm})$.

\section{CONCLUSION}

A new textile Wunderlich fractal dipole antenna is constructed with the second iteration. This antenna is modified utilizing the distribution of surface currents to make this antenna operate in RFID frequencies at 0.952 and $2.5 \mathrm{GHz}$. The proposed antenna is tested with two forms of substrate materials; conventional and textile. The performance of the proposed antenna is investigated by considering the effect of thread density by sweeping thread radius $\mathrm{mm}$ variation from $0.5-0.9 \mathrm{~mm}$. It is found that the density of the threads within the substrate antenna area decreased as the thread radius has been reduced.

\section{REFERENCES}

Abdulkarim, S.F., A.J. Salim, J.K. Ali, A.I. Hammoodi and M.T. Yassen et al., 2013. A compact Peano-type fractal based printed slot antenna for dual-band wireless applications. Proceedings of the IEEE International Conference on RF and Microwave (RFM'13), December 9-11, 2013, IEEE, Penang, Malaysia, ISBN:978-1-4799-2214-7, pp: 329-332.

Ali, J.K. and E.S. Ahmed, 2012. A new fractal based printed slot Antenna for dual band wireless communication applications. Proceedings of the Symposium on Progress in Electromagnetics Research(PIERS'12), March 27-30, 2012, Department of Electrical and Electronic Engineering, Kuala Lumpur, Malaysia, pp: 1518-1521.

Ali, J.K., 2009. A new microstrip-fed printed slot antenna based on Moore space-filling geometry. Proceedings of the Conference on Antennas \& Propagation (LAPC'09), November 16-17, 2009, IEEE, Loughborough, England, ISBN:978-1-4244-2720-8, pp: 449-452.

Ali, J.K., M.T. Yassen, M.R. Hussan and A.J. Salim, 2012. A printed fractal based slot antenna for multi-band wireless communication applications. Proceedings of the Symposium on Progress in Electromagnetics Research (PIERS'12), August 19-23, 2012, Moscow, Russia, pp: 618-622.

Ali, J.K., Z.A. AL-Hussain, A.A. Osman and A.J. Salim, 2012. A new compact size fractal based microstrip slot antenna for GPS applications. Proceedings of the Symposium on Progress in Electromagnetics Research (PIERS'12), March 27-30, 2012, Kuala Lumpur, Malaysia, pp: 700-703. 
Bernat, L. and N. Mansfield, 2008. Radio Frequency Identification (RFID): OECD policy guidance a focus on security and privacy, applications impacts and country initiatives. Proceedings of the OECD Ministerial Conference on Future of the Internet Economy, June 17-18, 2008, OECD, Seoul, Korea, pp: 71-80.

Hatem, G.M., A.J. Salim and J.K. Ali, 2014. Wearable sierpinski dragon fractal patch antenna for RFID applications. Proceedings of the 1st International Conference on Engineering Sciences Applications ICESA., December 22, 2014, University of Kerbala, Karbala, Iraq, pp: 24-25.

Hatem, G.M., A.J. Salim and J.K. Ali, 2015. An accurate technique to model the substrate of wearable textile antennas. Proceedings of the Symposium on Progress in Electromagnetics Research, July 6-9, 2015, PIERS, Prague, Czech Republic, pp: 122-124.
Jalil, M.E., M.A. Rahim, N.A. Samsuri and N.A. Murad, 2012. Triple band fractal Koch antenna for wearable application. Proceedings of the Symposium on Progress in Electromagnetics Research (PIERS'12), March 27-30, 2012, Electromagnetics Academy, Kuala Lumpur, Malaysia, pp: 1285-1289.

Jalil, M.E.B., M.K.A. Rahim, N.A. Samsuri, N.A. Murad and A.H. Majid et al., 2013. Fractal koch multiband textile antenna performance with bending, wet conditions and on the human body. Prog. Electromagnet. Res., 140: 633-652.

Poonkuzhali, R., Z.C. Alex and T.N. Balakrishnan, 2016. Miniaturized wearable fractal antenna for military applications at VHF band. Prog. Electromagnet. Res. C., 62: 179-190.

Sangeetha, M. and B.E. Caroline, 2016. A survey on fractal wearable antennas with different substrate materials. Intl. J. Appl. Eng. Technol., 2: 1-7.

Syed, U.U., R.K. Baghel and S. Siddiqi, 2015. Efficient wearable electro-textile antenna using Minkowski fractal geometry with tuning holes. Intl. J. Technol. Enhancements Emerging Eng. Res., 3: 39-41. 